\title{
EDITORIAL
}

\section{Implications of genomic imprinting for psychiatric genetics ${ }^{1}$}

The genetics of psychiatric disease continues to be puzzling; what, for instance, really is the mode of transmission of schizophrenia? Is it polygenic (Gottesman \& Shields, 1982)? Is it dominant but incompletely penetrant (Böök, 1953), or partly dominant with incomplete penetrance (Slater, 1958); does it involve two loci with epistasis (Matthysse \& Kidd, 1976), or is it none of these (O'Rourke et al. 1982)? To the cynical observer it may seem that by assuming an appropriate degree of penetrance or expressivity, any mode of inheritance can be made to fit. Possibly the disorders are heterogeneous, and understandable inheritance patterns would emerge if the correct subgroups could be identified; possibly more sophisticated analyses would help.

Whatever the reason, while a genetic contribution to the functional psychoses is now not in doubt, no one has yet come up with a satisfactory model to account for the observed segregation ratios found within pedigrees. Consequently, the discovery of a new mode of transmission associated with two rare childhood syndromes (the Prader-Willi and Angelman's syndromes) should be of considerable interest to anyone interested in psychiatric genetics.

Prader-Willi syndrome (PWS) accounts for about $1 \%$ of the causes of mental handicap; it is also characterized by infantile hypotonia, hypogenitalism, and a remarkable disorder of behaviour: a hyperphagia so extreme that sufferers can actually eat themselves to death (Butler, 1990). It is not surprising that, in a disorder with somatic abnormalities and mental handicap, chromosomal anomalies have been discovered, but difficulties in establishing clear criteria for diagnosis (a problem familiar to psychiatrists) as well as the technical complexities of high-resolution chromosome analysis led to controversial claims. In 1981, following a hint that chromosome 15 abnormalities were commoner than expected in PWS, Ledbetter et al. (1981) found that four out of five cases had lost the same small band near the centromere on the long arm (referred to as ' $q$ ') of this chromosome (an abnormality designated as affecting bands $15 q 11$ to $15 q 13$ ). Subsequent investigations confirmed that the 15q11-15q13 deletions were found in a large proportion of PWS, but while some research workers argued that if strict clinical criteria were applied then all PWS cases had chromosome 15 anomalies (Mattei et al. 1983; Niikawa \& Ishikiriyama, 1985), others contended that less than three-quarters of patients had the deletion detected by Ledbetter (Labidi \& Cassidy, 1986). Current opinion suggests that about $70 \%$ of PWS have deletions of $15 q 11-15 q 13$ (Butler, 1990).

If all cases of PWS could have been shown to have the same chromosomal abnormality, it would, of course, demonstrate beyond doubt that loss of genetic material in this region was the cause. Indeed, even if there was no abnormality seen down a microscope, research workers were content to believe that there were currently undetectable (sub-microscopic) deletions in such patients, thus preserving the established view that with only half the normal complement of DNA at $15 q 11-15 q 13$, PWS patients had reduced expression of some crucial protein (or proteins).

But there were problems with this view: a small number of PWS cases were found who, instead of a deletion in a critical region of chromosome 15, had three, and even four copies of 15q11-15q13 (partial trisomies and tetrasomies) (Mattei et al. 1983). Such anomalies were so rare that they could perhaps be successfully regarded as a separate subgroup (Butler et al. 1986), but a more disturbing discovery was made in Angelman's syndrome: the same chromosomal deletion appeared to be responsible.

On the face of it, there would seem to be little similarity between the Prader-Willi syndrome and

' Address for correspondence: Dr Jonathan Flint, Maudsley Hospital, Denmark Hill. London SE5. 
Angelman's syndrome (AS). Angelman's syndrome was first described less than thirty years ago and there are only about 90 cases reported in the world literature. The diagnosis is generally made before the age of five in a child with almost complete failure to talk, severe mental retardation, a jerky ataxia and inappropriate laughter (the last two features have earned the syndrome the description 'happy puppet') (Robb et al. 1989). Both PWS and AS syndromes have a large number of other features, and the clinical picture is varied, but no one had suspected that they might be related by cause, until two case reports demonstrated that patients with the clinical characteristics of AS had the same cytogenetic abnormalities as PWS (Kaplan et al. 1987; Magenis et al. 1987). About $60 \%$ of cases of AS have a cytogenetically identifiable deletion, and DNA analysis has failed to find consistent differences between PWS and AS (Donlon, 1988; Knoll et al. 1989; Imaizumi et al. 1990; Knoll et al. 1990; Magenis et al. 1990).

Of course, it remained possible to argue that there were small differences in the extent of the deletions in the two syndromes, and complex explanations based on this principle were put forward (Donlon, 1988); but they could not explain the observation, made in 1989, that when a deletion is found in PWS, it occurs on the chromosome inherited from the father, while the deletion detected in AS patients arises on the maternally inherited chromosome (Knoll et al. 1989). The point here is not that PWS is inherited from the father and that AS is inherited from the mother (inheritance of either syndrome has been only rarely documented (Baraitser et al. 1987; Cassidy, 1987; Willems et al. 1987)), but that when a de novo 15q11-13 deletion occurs on the paternal chromosome (i.e. in sperm), then the child will develop PWS, but when a similar deletion occurs on the maternal chromosome (i.e. in the ovum) then the child develops Angelman's syndrome. How can parental origin explain why two apparently identical chromosomal abnormalities give rise to such different syndromes?

An answer was suggested when the DNA of PWS patients with no cytogenetically detectable deletion was examined. Although the research workers could not rule out very small deletions, they effectively combed the crucial area of chromosome 15 and found nothing abnormal. The DNA is, it seems, intact; but when they came to look at the parental origin of the chromosomes in these nondeletion cases of PWS, they found that instead of the usual arrangement of one paternal and one maternal chromosome, the PWS patients had two maternal chromosomes (Nicholls et al. 1989). In other words, the lack of paternal genes on the long arm of chromosome 15 (at 15q11-13), whether this be due to a deletion on the paternal chromosome, or to the inheritance of two maternal chromosomes, leads to the development of PWS.

As it was already known that AS arises when there is loss of maternal chromosomal material (i.e. when only paternal genes were present) then the remarkable possibility arose that the same stretch of DNA, if inherited only from the mother, would cause PWS, and if inherited from the father, would cause AS. Unfortunately, it appears that the explanation may be more complex. Although some cases of non-deletion AS have now been reported where both copies of chromosome 15q are inherited from the father, this appears to be a rare event (Knoll et al. 1991). Nevertheless, it remains true that the integrity of DNA is not a guarantee of health: you also need to have a copy from each parent; even inheriting two copies from one parent is not sufficient.

In fact, this phenomenon is not new to genetics: parthenogenesis (asexual reproduction) has never been reported in mammals, and artificial attempts to induce it, by constructing mouse embryos solely from one parent's chromosomes, have failed (Surani \& Barton, 1983; Barton et al. 1984; Surani et al. 1984); for normal development, there has to be a chromosomal contribution from both parents (Surani, 1986; Solter, 1988). Because there is nothing in the DNA sequence to mark the parental origin of the chromosome, it was argued that the DNA in the germ line tissue was 'labelled', or 'imprinted' in some way (possibly by adding a methyl group to one of the pyrimidine bases, cytosine (Reik et al. 1987)). The process is known as genomic imprinting; it means that the extent of expression of a gene, that is the amount of its protein product, depends partly at least on whether that gene has a paternal or maternal origin. For instance, it could be that a certain gene, if inherited from the father, is only expressed at a small fraction of the level of exactly the same gene inherited from the mother.

No one has yet explained why genomic imprinting occurs. It has only been found in placental 
mammals and in flowering plants (angiosperms); the significant common feature appears to be that their offspring are nourished directly by maternal tissue. Interestingly, the hydatidiform mole, a placental malformation characterized by an overgrowth of placental tissues with absent or disorganized foetal material, has only paternal chromosomes (Sulzman \& Surti, 1984), whereas the ovarian teratomas derived from all three germ layers have only maternal chromosomes (Linder et al. 1975). On the bases of these and similar observations, it has been suggested that genomic imprinting occurs to restrain the proliferative growth of nutrient tissues (Hall, 1990; Moore \& Haig, 1991).

How important is genomic imprinting in human genetics? Does it, for instance, occur in inherited conditions? PWS and AS are rarely inherited (Baraitser et al. 1987; Cassidy, 1987; Willems et al. 1987), and in PWS imprinting only has an effect, and was only noticed, because of chromosomal abnormalities (a deletion or an illegitimate segregation which results in an individual only having DNA from one parent). Although these events may not be as rare as sometimes supposed (Voss et al. 1989), they do not commonly occur in inherited disorders. Is imprinting only significant in conditions where chromosomal rearrangements have been causally implicated?

Work on mice suggests this is unlikely to be the case; genes have been identified where the level of expression (and hence the mouse's phenotype) depends on whether the gene sits on a maternal or a paternal chromosome (Barlow et al. 1991; DeChiara et al. 1991). Theoretically, therefore, a gene (responsible for a disease) might be expressed only after it has passed through a male germ line. This would produce a remarkable pedigree. Imagine a family where all the children are daughters and half of them had inherited the 'disease gene' from their father; they would have the disease, but none of their own children would be affected. The disease appears to be dominantly inherited in the first generation, but has skipped the next generation. This pattern cannot be explained by dominant or recessive inheritance.

Do such pedigrees exist, and could they be important in psychiatric genetics? It is almost axiomatic in the history of science that research workers only see what they already know (hence, presumably, why researchers re-search), which is precisely the moral of this tale of two syndromes. In PWS it was known by 1983 that the deletion occurred on the paternal chromosome (Butler \& Palmer, 1983), but it took six more years before imprinting was invoked as an explanation (Knoll et al. 1989), even though genomic imprinting had been described in mice in 1984 (Barton et al. 1984; Surani et al. 1984). This suggests that it may be worth re-examining even the most well-worked ground from a new perspective. Consider, for instance, Huntington's disease.

Huntington's disease is a well known example of a dominantly inherited genetic disorder, yet although the mode of inheritance has textbook status, it does not explain all the known characteristics of Huntington's disease pedigrees. For instance, there has been controversy over the observation that the age of onset of the disease appears to become progressively younger in successive generations (a phenomenon called anticipation). As no genetic mechanism could account for this, it has been dismissed as an artefact. However, it is impossible to ignore a frequently reported finding that age of onset is much earlier (that is anticipation is more marked) when the disease is inherited from the father (Bird et al. 1974; Newcombe et al. 1981; Myers et al. 1982; Boehnke et al. 1983), although this only occurs in 5 to $10 \%$ of all families (Ridley et al. 1988). This looks like a perfect example of genomic imprinting: the level of expression of a gene is being determined, at least in part, by its transmission through the parental germ line (Reik, 1988; Ridley et al. 1988). But as 5-20\% of juvenile onset patients have inherited the gene from their mother, there may be a more complex explanation (Laird, 1990).

Huntington's disease is not the only case where the severity of expression of disease has been reported to be affected by parental origin. Following the recognition that maternal and paternal chromosomes function differently, the phenomenon has been seen in a number of disorders; for instance, spinocerebellar ataxia, neurofibromatosis (types I and II), myotonic dystrophy, and cerebellar ataxia (Hall, 1990). However, in none of these cases has a pedigree been reported as unusual as the imaginary one described above. Could this again be for lack of looking? There is one example (again from psychiatric genetics) that perhaps supports such a view.

When lymphocytes are grown in folate deficient medium, gaps and breaks are observed in mitotic 
chromosomes (Sutherland, 1977a). Some of these breaks are heritable and one, on the X chromosome, is associated with mental retardation (Sutherland 1977b; Turner et al. 1978), although in affected individuals seldom more than $50 \%$ of cells show the characteristic constriction at the tip of the long arm of the $X$ chromosome. The 'fragile $X$ ' syndrome, as it became known, in addition to a variety of physical abnormalities turned out to have a complex neuropsychiatric phenotype: schizoaffective and major affective illness have been found in fragile X kindreds (Reiss et al. 1986, 1988), and autistic spectrum disorders occur in males positive for fragile X (Brown et al. 1982, 1986; Hagerman et al. 1986). The fragile $X$ syndrome is now reckoned to be the commonest cause of inherited mental handicap (Gustavson et al. 1986; Webb et al. 1986).

It will come as no surprise to learn that fragile $\mathrm{X}$ syndrome is an $\mathrm{X}$-linked condition. From a Mendelian standpoint, when a male inherits an X-linked condition, because he has only one $\mathrm{X}$ chromosome and must express its genes, he will suffer from that disorder. It was, therefore, unsettling to find that as many as $20 \%$ of males inheriting the fragile $\mathrm{X}$ mutation do not experience the syndrome; moreover, pedigrees are known where daughters who inherit the fragile $\mathrm{X}$ mutation from their unaffected (non-penetrant) fathers are asymptomatic, but their sons have all the features of the syndrome (Sherman et al. 1984, 1985). In order to be expressed, the mutant gene has to be passed through a female, a case that seems to fit into the pattern predicted for genomic imprinting described above. Thus, it has been argued (Laird, 1987) that unaffected males who have inherited a non-imprinted fragile $\mathrm{X}$ chromosome from their mothers pass on the non-imprinted chromosome to their daughters, who are also, therefore, symptom free. However, the next generation stands to suffer, possibly because in the female germ line, during oogenesis, the imprint is lost as a result of partial reactivation of the $\mathrm{X}$ chromosome (in females one of the two $\mathrm{X}$ chromosomes is randomly inactivated, except in the primary oocytes in the ovary where both $\mathrm{X}$ chromosomes are active). Recently, molecular biological evidence has emerged to support the imprinting hypothesis: methylation, a reversible modification DNA, is associated with the expression of the disease, and methylation is a candidate for the 'label' that imprints DNA (Bell et al. 1991; Vincent et al. 1991).

Once this type of inheritance pattern is recognized, then the variability of the fragile $\mathrm{X}$ phenotype begins to be more comprehensible. When Reiss et al. (1989) assessed various measures of social, psychological and educational functioning in fragile $\mathrm{X}$ females, they were able to show significant subgroup differences by dividing their subjects according to the presence of imprinted or nonimprinted X chromosomes (as deduced from the inheritance pattern and the fragile X karyotype). It emerged that women who had inherited an imprinted fragile $X$ chromosome had significantly more schizotypal features (in addition to social and educational disabilities) than controls or nonimprinted fragile $X$ heterozygotes. Without an awareness of imprinting, this pattern would have gone unrecognized. It implies a hitherto unexpected genetic cause for these diverse disabilities, including schizophrenia-spectrum disorders.

This of course returns us to the tantalizing prospect raised at the beginning of this paper: could some of the remarkable variation in the expression or penetrance of the genes responsible for the functional psychoses be due to genomic imprinting? Until the question of parental origin of psychiatric disease is regularly asked, until people begin to expect patterns of inheritance that are not simply recessive or dominant (instead of attempting to fit whatever is observed into one of the known modes of transmission), we will not know. What should be emphasized is that work on the rarer syndromes, on the clinical obscurities such as Angelman's syndrome, is showing that not all inheritance patterns in human genetic disease can be explained as dominant or recessive. Genomic imprinting is one alternative mode of inheritance, and it is almost certainly not the only one. The remarkable sensitivity of the new polyermase chain reaction technique has already led to the demonstration that somatic mosaicism (Hall, 1988) and mitochondrial inheritance (Wallace, 1989) have roles to play in human genetic disease, and even that classic example of dominant inheritance, Huntington's disease, turns out not to be all it at first appeared to be (Laird, 1990). 


\section{REFERENCES}

Baraitser, M., Patton, M., Lam, S. T. S., Brett, E. M. \& Wilson, J. (1987). The Angelman ('happy puppet') syndrome: is it autosomal recessive? Clinical Genetics 31, 323-330.

Barlow, D. P., Stöger, R., Herrmann, B. G., Saito, K. \& Schweifer, N. (1991). The mouse insulin-like growth factor type-2 receptor is imprinted and closely linked to the Tme locus. Nature 349, 84-87.

Barton, S. C., Surani, M. A. H. \& Norris, M. C. (1984). Role of paternal and maternal genomes in mouse development. Nature $311,374376$.

Bell, M. V., Hirst, M. C., Nakahori, Y., MacKinnon, R. N., Roche, A., Flint, T. J., Jacobs, P. A., Tommerup, N., Tranebjaerg, L., Froster-Iskenius, U., Kerr, B., Turner, G., Lindenbaum, R. H., Winter, R., Pembrey, M., Thibodeau, S. \& Davies, K. E. (1991). Physical mapping across the fragile $X$ : hypermethylation and clinical expression of the fragile $X$ syndrome. Cell 64, 861-866.

Bird, E. D., Caro, A. J. \& Pilling, J. B. (1974). A sex-related factor in the inheritance of Huntington's chorea. Annals of Human Genetics 37, 255-260.

Boehnke, M., Conneally, P. M. \& Lange, K. (1983). Two models for a maternal factor in the inheritance of Huntington disease. American Journal of Human Genetics 35, 845-860.

Böök, J. A. (1953). A genetic and neuropsychiatric investigation of a North Swedish population. Acta Genetica (Basel) 4, 1-100.

Brown, W. T., Friedman, E., Jenkins, E. C., Brooks, J., Wisniewski, K., Raguthu, S. \& French, J. H. (1982). Association of fragile X syndrome with autism. Lancet i, 100.

Brown, W. T., Jenkins, E. C., Cohen, I. L., Fisch, G. S., Wilf-Schein, E. G., Gross, A., Waterhouse, L., Fein, D., Mason-Brothers, A. \& Ritvo, E. (1986). Fragile $X$ and autism: a multicenter survey. American Journal of Medical Genetics 23, 341-352.

Butler, M. G. (1990). Prader Willi syndrome: current understanding of cause and diagnosis. American Journal of Medical Genetics 35, $319-332$.

Butler, M. G. \& Palmer C. G. (1983). Parental origin of chromosome 15 in Prader Willi syndrome. Lancet i, 1285-1286.

Butler, M. G., Meaney, F. J. \& Palmer, C. G. (1986). Clinical and cytogenetic survey of 39 individuals with Prader-Labhart-Willi syndrome. American Journal of Medical Genetics 23, 793-809.

Cassidy, S. B. (1987). Recurrence risk in Prader-Willi syndrome. American Journal of Medical Generics 28, 59-60.

DeChiara, T. M., Robertson, E. J. \& Efstratiadis, A. (1991). Parental imprinting of the mouse insulin-like growth factor II gene. Cell 64, 849859.

Donlon, T. A. (1988). Similar molecular deletions on chromosome $15 q 11.2$ are encountered in both the Prader-Willi and Angelman syndromes. Human Genetics 80, 322-328.

Gottesman, I, I. \& Shields, J. (1982). Schizophrenia. The Epigenetic Puzzle. Cambridge University Press: Cambridge.

Gustavson, K.-H., Blomquist, H. \& Holmgren, G. (1986). Prevalence of fragile- $X$ syndrome in mentally retarded boys in a Swedish county. American Journal of Medical Genetics 23, 581-588.

Hagerman, R. J., Jackson, S. W., Levitas, A., Rimland, B. \& Braden, M. (1986). An analysis of autism in fifty males with the fragile $X$ syndrome. American Journal of Medical Genelics 23, 359-374.

Hall, J. G. (1988). Review and hypotheses: somatic mosaicism: observations related to clinical genetics. American Journal of Human Genetics 43, 355-363.

Hall, J. G. (1990). Genomic imprinting: review and relevance to human disease. American Journal of Human Genetics 46, 857-873.

Imaizumi, K., Takada, F., Kuroki, Y., Naritomi, K., Hamabe, J. \& Niikawa, N. (1990). Cytogenetic and molecular study of the Angelman syndrome. American Journal of Medical Genetics 35, 314.318.

Kaplan, L. C., Wharton, R., Elias, E., Mandell, F., Donlon, T. \& Latt, S. A. (1987). Clinical heterogeneity associated with deletions in the long arm of chromosome 15: report of 3 new cases and their possible genetic significance. American Journal of Medical Genetics 28, 45-53.
Knoll, J. H. M., Nicholls, R. D., Magenis, R. E., Graham, J. M., Lalande, M. \& Latt, S. A. (1989). Angelman and Prader-Willi syndromes share a common chromosome 15 deletion bul differ in parental origin of the deletion. American Journal of Medical Genetics 32, 285-290.

Knoll, J. H. M., Nicholls, R. D., Magenis, R. E., Glatt, J., Graham, J. M., Kaplan, L. \& Lalande, M. (1990). Angelman syndrome: three molecular classes identified with chromosome $15 q 1 / \mathrm{q} 13$. specific DNA markers. American Journal of Human Genetics 47, 149-155.

Knoll, J. H. M., Glatt, K. A., Nicholls, R. D., Malcolm, S. \& Lalande, M. (1991). Chromosome 15 uniparental disomy is not frequent in Angelman syndrome. American Journal of Human Genetics 48, 16-21.

Labidi, F. \& Cassidy, S. B. (1986). A blind prometaphase study of Prader-Willi syndrome: frequency and consistency in interpretation of del 15q. American Journal of Human Genetics 39, 452-460.

Laird, C. D. (1987). Proposed mechanism of inheritance and expression of the human fragile- $X$ syndrome of mental retardation. Genetics 117, 587-599.

Laird, C. D. (1990). Proposed genetic basis of Huntington's disease. Trends in Genetics 6, 242-247.

Ledbetter, D. H., Riccardi, V. M., Airhart, S. D., Strobel, R. J., Keenan, B. S. \& Crawford, J. D. (1981). Deletions of chromosome 15 as a cause of the Prader Willi syndrome. New England Journal of Medicine 304, 325-329.

Linder, D., McCaw, B. K. \& Hecht, F. (1975). Parthenogenetic origin of benign ovarian teratomas. New England Journal of Medicine 292, 63-66.

Magenis, R. E., Brown, M. G., Lacy, D. A., Budden, S. \& LaFranchi, S. (1987). Is Angelman syndrome an alternate result of del(15)(q11q13)? American Journal of Medical Genetics 28, 829-838.

Magenis, R. E., Toth-Fejel, S., Allen, L. J., Black, M., Brown, M. G., Budden, S., Cohen, R., Friedman, J. M., Kalousek, D., Zonana, J., Lacey, D., LaFranchi, S., Lahr, M., Macfarlane, J. \& Williams, C.P.S. (1990). Comparison of the $15 q$ deletions in Prader-Willi and Angelman syndromes: specific regions, extent of deletions, parental origin and clinical consequences. American Journal of Medical Genetics 35, 333.349.

Mattei, J. F., Mattei, M. G. \& Giraud, F. (1983). Prader-Willi syndrome and chromosome 15. Human Genetics 64, 356-362.

Matthysse, S. W. \& Kidd, K. K. (1976). Estimating the genetic contribution to schizophrenia. American Journal of Psychiarry 133, 185-191.

Moore, T. \& Haig, D. (1991). Genomic imprinting in mammalian development: a parental tug of war. Trends in Genetics 7, 45-49.

Myers, R. H., Madden, J. J., Teague, J. C. \& Falek, A. (1982). Factors related to onset age of Huntington disease. American Journal of Human Genetics 34, 481-488.

Newcombe, R. G., Walker, D. A. \& Harper, P. S. (1981). Factors influencing age at onset and duration of survival in Huntington's chorea. Annals of Human Genetics 45, 387-396.

Nicholls, R. D., Knoll, J. H. M., Butler, M.G., Karam, S. \& Lalande, $M$. (1989). Genetic imprinting suggested by maternal heterodisomy in non-deletion Prader-Willi syndrome. Nature 342, 281-285.

Niikawa, N. \& Ishikiriyama, S. (1985). Clinical and cytogenetic studies of Prader-Willi syndrome : evidence of phenotype-karyotype correlation. Human Genetics 69, 22-27.

O'Rourke, D. H., Gottesman, I. I., Suarez, B. K., Rice, J. \& Reich, T. (1982). Refutation of the general single locus model for the etiology of schizophrenia. American Journal of Human Genetics 34, 630-649.

Reik, W. (1988). Genomic imprinting: a possible mechanism for the parental origin effect in Huntington's chorea. Journal of Medical Genetics 25, 805-808.

Reik, W., Collick, A., Norris, M. L., Barton, S. C. \& Surani, M. A. H. (1987). Genomic imprinting determines methylation of parental alleles in transgenic mice. Nature 328, 248-251.

Reiss, A. L., Feinstein, C., Toomey, K., Rosenbaum, K., Goldsmith, 
B. \& Borengasser-Caruso, M. A. (1986). Psychiatric disability associated with the fragile $\mathrm{X}$ chromosome. American Journal of Medical Genetics 23, 393-402.

Reiss, A. L., Hagerman, R. J., Vinogradov, S., Abrams, M. \& King, R. (1988). Psychiatric disability in female carriers of the fragile $X$ chromosome. Archives of General Psychiatry 45, 25-30.

Reiss, A. L., Freund, L., Vinogradov, S., Hagerman, R. \& Cronister, A. (1989). Parental inheritance and psychological disability in fragile $X$ females. American Journal of Human Genetics 45, 697-705.

Ridley, R. M., Frith, C. D., Crow, T. I. \& Conneally, P. M. (1988) Anticipation in Huntington's disease is inherited through the male line but may originate in the female. Journal of Medical Genetics 25, 589-595.

Robb, S. A., Pohl, K. R. E., Baraitser, M., Wilson, J. \& Brett, E. M. (1989). The 'happy puppet' syndrome of Angelman: review of the clinical features. Archives of Disease in Childhood 64, 83-86.

Sherman, S. L., Morton, N. E., Jacobs, P. A. \& Turner, G. (1984). The marker (X) syndrome: a cytogenetic and genetic analysis. Annals of Human Genetics 48, 21-37.

Sherman, S. L., Jacobs, P. A., Morton, N. E., Froster-Iskenius, U., Howard-Peebles, P. N., Nielsen, K. B., Partington, M. W., Sutherland, G. R., Turner, G. \& Watson, M. (1985). Further segregation analysis of the fragile $\mathrm{X}$ syndrome with special reference to transmitting males. Human Genetics 69, 289-299.

Slater, E. (1958). The monogenic theory of schizophrenia. Acta Genetica (Basel) 8, 50-56.

Solter, D. (1988). Differential imprinting and expression of maternal and paternal genomes. Annual Review of Genetics 22, 127-146.

Sulzman, A. E. \& Surti, U. (1984). Complete and partial hydatidiform moles: cytogenetic and morphological aspects. In Human Trophoblast Neoplasms (ed. R. A. Pattillo and P. O. Hussa), pp. 135-145. Plenum: New York.

Surani, M. A. H. (1986). Evidences and consequences of differences between maternal and paternal genomes during embryogenesis in the mouse. In Experimental Approaches to Mammalian Embryonic Development (ed. J. Rossan and R. A. Pederson), pp. 401-435. Cambridge University Press: Cambridge.

Surani, M. A. H. \& Barton, S. C. (1983). Development of gynogenetic eggs in the mouse: implications for parthenogenetic embryos. Science 222, 1034-1036.

Surani, M. A. H., Barton, S. C. \& Norris, M. L. (1984). Development of reconstituted mouse eggs suggests imprinting of the genome during gametogenesis. Nature 308, 548-550.

Sutherland, G. R. (1977a). Heritable fragile sites on human chromosomes. Demonstrations of their dependence on the type of tissue culture medium. Science 197, 265-266.

Sutherland, G. R. (1977b). Marker X chromosome and mental retardation. New England Journal of Medicine 296, 1415.

Turner, G., Till, R. \& Daniel, A. (1978). Marker X chromosomes, mental retardation and macro-orchidism. New England Journal of Medicine 299, 1472.

Vincent, A., Heitz, D., Petit, C., Kretz, C., Oberle, I. \& Mandel, J.-L. (1991). Abnormal pattern detected in fragile $X$ patients by pulse field gel electrophoresis. Nature 349, 624-626.

Voss, R., Ben-Simon, E., Avital, A., Godfrey, S., Zlotogora, J. Dagan, J., Tikochinski, Y. \& Hillel, J. (1989). Isodisomy of chromosome 7 in a patient with cystic fibrosis: could uniparental disomy be common in humans? American Journal of Human Genetics 45, 373-380.

Wallace, D. C. (1989). Mitochondrial DNA mutations and neuromuscular disease. Trends in Genetics 5, 9-13.

Webb, T. P., Bundey, S. E., Thake, A. L. \& Todd, J. (1986) Population incidence and segregation ratios in the Martin Bel syndrome. American Journal of Medical Genetics 23, 573.580.

Willems, P. J., Dijkstra, I., Brouwer, O. F. \& Smit, G. P. A. (1987). Recurrence risk in the Angelman ('happy puppet') syndrome. American Journal of Medical Genetics 27, 773-780. 